\title{
Padrão Fenológico de Attalea maripa (Aubl.) Mart. em Áreas de Pastagens na Amazônia Oriental
}

\author{
Helaine Cristine Gonçalves Pires ${ }^{1}$, Leonilde dos Santos Rosa ${ }^{1}$, \\ Benedito Silva Cabral ${ }^{1}$, Viviane Martins da Silva ${ }^{1}$, Glauco André Nogueira ${ }^{1}$, \\ Paulo Ricardo Neves Ferreira ${ }^{1}$ \\ ${ }^{1}$ Instituto de Ciências Agrárias, Universidade Federal Rural da Amazônia - UFRA, Belém/PA, Brasil
}

\section{RESUMO}

A pesquisa avaliou a fenologia de Attalea maripa (inajá), relacionando os eventos fenológicos com a precipitação pluviométrica. Os dados foram obtidos em 100 palmeiras adultas provenientes de regeneração natural, em 3,25 hectares de área de pastagens em Bonito, PA, no período de agosto de 2009 a dezembro de 2011. Os dados foram analisados por meio de fenogramas, índice de sincronia e análise fatorial. Pelo que a pesquisa evidenciou, o padrão fenológico do inajá não é sazonal. A floração e a frutificação ocorrem durante todo o ano; são eventos de longa duração, que sofrem oscilações ao longo do ano. A fenofase espata fechada é altamente sincrônica. A frutificação é um evento fenológico pouco sincrônico. A precipitação é um fator climático importante para a fenologia do inajá, pois afeta negativamente a produção de espata aberta com flores e a queda de folhas e positivamente a queda de frutos maduros.

Palavras-chave: inajá, floração, frutificação, sincronia.

\section{Phenological Pattern of Attalea maripa (Aubl.) Mart. in Pastures Areas of the Eastern Amazon}

\begin{abstract}
The research evaluated the Attale amaripa (inajá) phenology relating the phenological events with rainfall. Data were obtained from 100 adult palms from natural regeneration in 3.25 acres of pasture in Bonito-PA, from August 2009 to December 2011. Data were analyzed using phenograms, synchrony index and factor analysis. The research showed that the phenological pattern of inajá is not seasonal. Flowering and fruiting occur throughout the year and are long-lasting events and suffer fluctuations throughout the year. The closed spathe phenology is highly synchronous. The fruiting is a slightly synchronous phenological event. Rainfall is a major climatic factor for phenology inajá because negatively affects production of open spathe with flowers and leaves fall and positively mature fruit drop.
\end{abstract}

Keywords: inajá, flowering, fruiting, synchrony. 


\section{INTRODUÇÃO}

A Fenologia é o ramo da Ecologia considerado fundamental para o entendimento da dinâmica das comunidades vegetais, pois facilita o entendimento dos processos de regeneração e reprodução das espécies em comunidades, das interações entre planta e animal, das estratégias para o uso sustentável de espécies vegetais e da geração de bioindicadores para avaliação de impactos climáticos (Tannus et al., 2006).

Apesar da sua importância, pesquisas sobre o padrão fenológico de espécies nativas com grande potencial econômico da Amazônia são escassas. Dentre essas espécies, encontra-se a Attalea maripa (Aubl.) Mart. (inajá), da família Arecaceae, com vasta ocorrência nessa região e que se desenvolve naturalmente em florestas secundárias e em pastagens, apresentando, portanto, grande potencial para a recuperação de áreas degradadas, seja na forma de monocultivo ou de sistema silvipastoril.

$\mathrm{Na}$ fase adulta, a palmeira inajá apresenta estipe ereto, simples e cilíndrico sem perfilhos; solitária, atinge na fase adulta até $13 \mathrm{~m}$ de altura e quase $57 \mathrm{~cm}$ de diâmetro à altura do peito (Matos, 2010). Do seu fruto é extraído óleo de cor clara transparente e com propriedades físico-químicas excelentes para a culinária, produção de biocombustível e outros produtos industriais (Mota \& França, 2007).

A despeito do seu grande potencial oleaginoso, sua população natural é constantemente alvo de queimadas durante o preparo de áreas agrícolas e limpeza de pasto nessa região (Matos, 2010). Assim, dada essa situação, torna-se necessário avançar em direção ao seu manejo sustentável. Não obstante, faltam pesquisas básicas sobre essa palmeira como, por exemplo, informações sobre o seu padrão fenológico.

Tendo isso em vista, esta pesquisa teve por objetivo avaliar a fenologia de Attalea maripa, relacionando os dados fenológicos com a precipitação pluviométrica, visando gerar subsídios para o manejo sustentável e conservação de sua população natural nas áreas naturais de ocorrência, na Amazônia.

\section{MATERIAL E MÉTODOS}

A pesquisa foi desenvolvida em Bonito (1'23'08'S; $1^{\circ} 23^{\prime} 24^{\prime \prime}$ e e 47021'56”; 47²2'12”W), no Estado do Pará, Brasil. O município apresenta temperatura média anual em torno de $25{ }^{\circ} \mathrm{C}$, umidade relativa do ar em torno de $80 \%$ e regime pluviométrico em torno de $2.250 \mathrm{~mm} / \mathrm{ano}$. Predominam nesse município latossolos amarelos e concrecionários lateríticos. A vegetação remanescente é composta por floresta secundária (IDESP, 2011).

Os dados foram obtidos de 100 palmeiras adultas em fase reprodutiva, provenientes de regeneração natural, em uma área de 3,25 hectares de pastagem. O monitoramento fenológico foi realizado mensalmente, por um período de 29 meses, de agosto de 2009 a dezembro de 2011.

A metodologia empregada foi baseada em Ruiz \& Alencar (2004). Foram registradas as seguintes fenofases: espata fechada, espata aberta com flores, espata aberta com flores caindo, espata aberta com flores caídas, cacho com frutos verdes, cacho com frutos maduros, cacho com frutos maduros caindo, indivíduos sem cacho, emissão de folhas novas e queda de folhas velhas.

Inicialmente foi calculada a percentagem de indivíduos que apresentaram eventos fenológicos e elaborados fenogramas. Em seguida, foi calculado o Índice de Sincronia (Z) para as fenofases de floração e frutificação, segundo Augspurger (1983). Posteriormente, os dados foram analisados por correlação de Spearman $(r s)$ e análise fatorial pelo método de componentes principais, utilizando-se o critério Varimax. A adequação desse método foi realizada pelos testes de Kaiser-Meyer-Olkin (KMO) e de Esfericidade de Bartlett (Hair et al., 2009). Os dados foram analisados com o auxílio do programa Statistical Package for the Social Sciences (SPSS $17.0^{\circ}$ ).

\section{RESULTADOS E DISCUSSÃO}

Durante o período de monitoramento foi observado que 82 das 100 palmeiras adultas de inajá avaliadas floresceram, frutificaram, apresentaram queda de folhas velhas e emitiram folhas novas. O percentual restante não apresentou estruturas reprodutivas.

A ausência de estruturas reprodutivas em palmeiras tropicais também foi constatada por Ruiz \& Alencar (2004), ao pesquisarem a fenologia da espécie Oenocarpus bataua, durante 16 anos, na Reserva Florestal Adolpho Ducke, Manaus, AM. Os autores verificaram que a ocorrência de indivíduos adultos sem cachos variou de $1 \%$ a $9 \%$, valor inferior ao obtido para o inajá, que foi de $15,9 \%$. 
A floração do inajá tem início com a emissão de espatas fechadas e o término acontece com a fenofase espata aberta com flores caídas. Ao longo do monitoramento fenológico na área de estudo em Bonito, PA, foi observada a ocorrência simultânea de floração e de frutificação em um mesmo indivíduo, fato esse também constatado por Matos (2010) ao estudar a biometria e morfologia de inajá em sistema silvipastoril no nordeste paraense.

Os índices de sincronia calculados para as fenofases de floração e frutificação foram em geral baixos (espata fechada $Z=0,78$; espata aberta com flores $Z=0,19$; espata aberta com flores caindo $Z=0,39$; espata aberta com flores caídas $Z=0,32$; cacho com frutos verdes $Z=0,42$; cacho com frutos maduros $Z=0,27$; e cacho com frutos maduros caindo $Z=0,21$ ), exceto para espata fechada, que apresentou alta sincronização.
A assincronia da maioria das fenofases avaliadas pode ser consequência do período prolongado de floração e de frutificação do inajá.

Pesquisas realizadas com outras espécies do gênero Attalea revelaram que a floração e a frutificação são, geralmente, assincrônicas ou pouco ou moderamente sincrônicas (Henderson et al., 2000; Adler \& Lambert, 2008), aproximando-se dos resultados obtidos para o inajá. Do mesmo modo, indivíduos de Astrocaryum aculeatissimum (Schott) Burret também não apresentaram sincronia de floração.

A emissão de espatas fechadas ocorreu durante todo o período da pesquisa de campo (Figura 1a). A maior produção ocorreu no período de julho a novembro, meses menos chuvoso, porém o pico ocorreu em julho (78\%), cuja precipitação pluviométrica média mensal foi igual a $153,35 \mathrm{~mm}$. A menor produção $(51,5 \%)$ foi
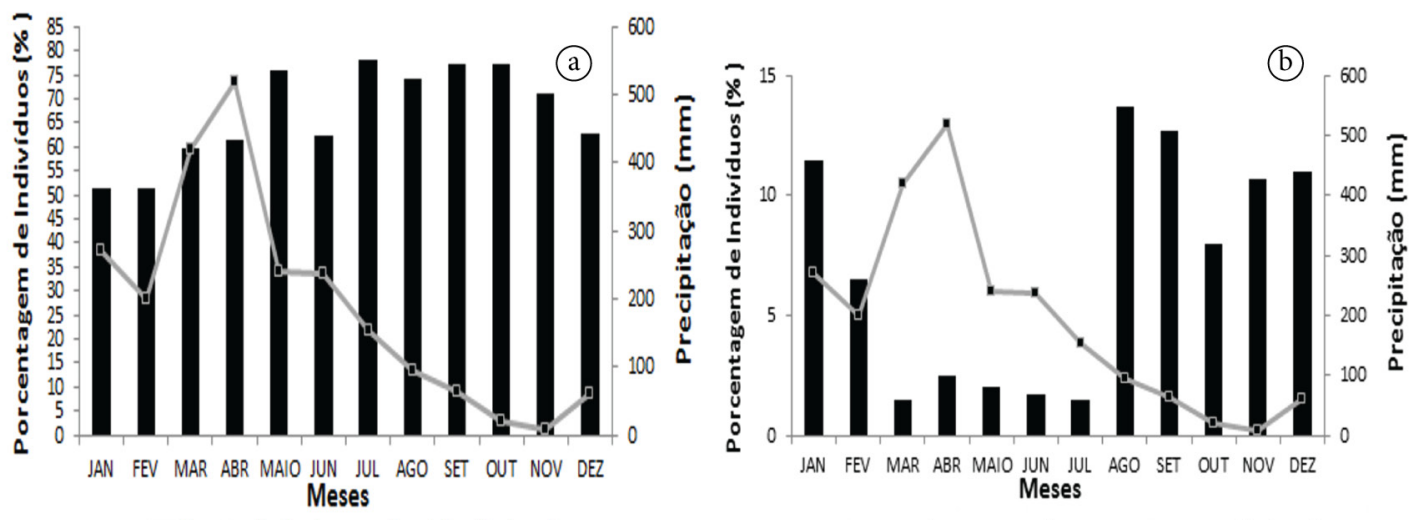

Espatas fechadas -Precipitação $(\mathrm{mm})$

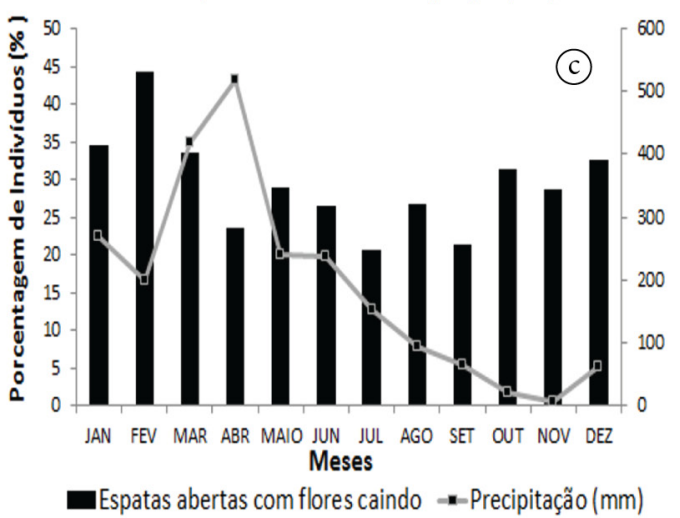

-Espatas abertas com flores -Precipitação(mm)

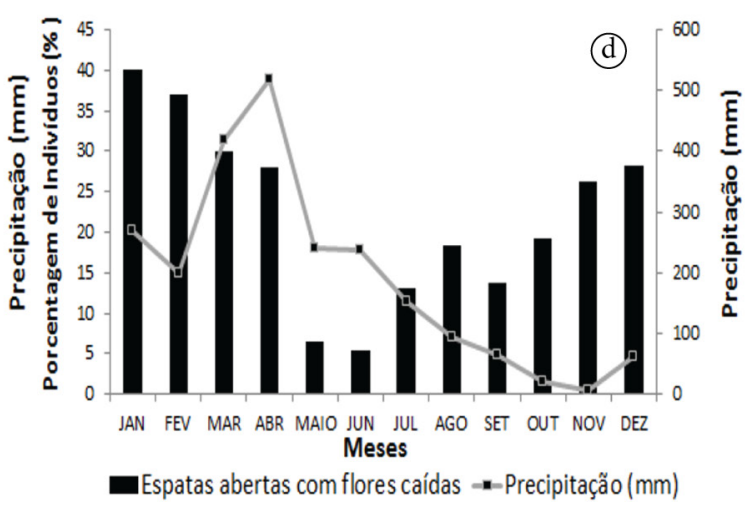

Figura 1. Percentagem de indivíduos de Attalea maripa (inajá) com espatas fechadas (1a), espatas abertas com flores (1b), espatas abertas com flores caindo (1c) e espatas abertas com flores caídas (1d), no período de agosto de 2009 a dezembro de 2011, em Bonito, PA.

Figure 1. Percentages of individuals Attalea maripa (inajá) with closedspathes (1a), open spathes with flowers (1b), open spathes with flowers falling (1c) and spathes open with fallen flowers (1d), from August 2009 to December 2011 , in Bonito-PA. 
registrada em janeiro e fevereiro, no período chuvoso, com precipitação média mensal de $271 \mathrm{~mm}$ e 199 mm, respectivamente.

A análise de correlação entre a emissão de espatas fechadas de inajá e a precipitação pluviométrica foi baixa, negativa e não significativa ( $r s=-0,14 ; \mathrm{p}>0,05)$, revelando que esse evento fenológico pode estar relacionado à ação de outros fatores climáticos como a temperatura, a insolação ou, ainda, às condições endógenas, em face da deficiência de nutrientes no solo. Estudos realizados no local da pesquisa revelaram que o solo na área de estudo apresenta baixa fertilidade natural (Vieira, 2011).

Diferentemente do inajá, pesquisas sobre a fenologia de patauá, em Manaus, AM, revelaram que a porcentagem de espatas fechadas foi baixa $(13,9 \%)$, em decorrência da baixa eficiência reprodutiva dessa palmeira e de prováveis ataques de pragas (Ruiz \& Alencar, 2004).

O inajá apresentou a fenofase espata aberta com flores durante os três anos de avaliação. Os maiores percentuais de indivíduos apresentando essa fenofase foram observados nos meses de agosto $(13,7 \%)$ e setembro (12,7\%), ambos no período menos chuvoso, com precipitação média mensal de 94,7 mm e $64,4 \mathrm{~mm}$, respectivamente. O menor percentual $(1,5 \%)$ ocorreu em março e julho, com precipitação de 419,4 mm e 153,35 mm, respectivamente (Figura $1 \mathrm{~b}$ ).

A baixa produção de espatas abertas com flores de inajá observada em Bonito, PA, deve-se, provavelmente, ao fato desse evento fenológico ser pouco sincrônico e sofrer influência da precipitação pluviométrica. Em relação a esse último aspecto, a análise de correlação, apesar de ser baixa $(r s=-0,39 ; p<0,05)$ indica que a precipitação afetou de forma negativa esse evento fenológico.

A fenofase espata aberta com flores caindo foi registrada em todo o período de estudo (Figura 1c), com maior produção $(44,3 \%)$ no mês de fevereiro, precipitação média de $271 \mathrm{~mm}$, e menor (20,7\%) em julho, no início do período de menor precipitação, média igual a $153,4 \mathrm{~mm}$.

A correlação entre a precipitação e a fenofase espata aberta com flores caindo foi negativa, próxima a zero e não significativa ( $r s=-0,052 ; p>0,05)$, sugerindo que a precipitação não foi o principal fator que favoreceu a queda de flores de inajá.
Ruiz \& Alencar (2004) também não obtiveram nenhuma correlação significativa entre a fenofase espatas abertas com flores caindo e precipitação para a palmeira patauá em Manaus, AM.

Cabe mencionar que, durante o período de avaliação fenológica dessa palmeira, foi registrada a ocorrência de polinizadores (abelhas), indicando que o inajá apresenta polinização entomófila. Em relação a esse aspecto, pesquisas realizadas na Amazônia e em outras regiões brasileiras associam a importância da polinização de palmeiras por abelhas ao sucesso da floração (Henderson et al., 2000; Ostrorog \& Barbosa, 2009; Rech \& Absy, 2011).

Assim, a queda de flores de inajá pode ter sido causada pela ação de outros fatores climáticos, como temperatura e insolação, ou mesmo pelo longo período de floração, ou, ainda, pela ação de fatores bióticos, como baixa frequência de agentes polinizadores devida aos altos índices pluviométricos observados no período chuvoso.

A fenofase espata aberta com flores caídas ocorreu em todo o período de monitoramento. A maior queda foi observada no mês de janeiro, período chuvoso (40\%) com precipitação pluviométrica média igual a $271 \mathrm{~mm}$, e a menor no mês de junho (5,5\%), cuja precipitação pluviométrica mensal alcançou, em média, 237,65 mm (Figura 1d).

A análise de correlação entre a variável fenofase flores caídas de inajá e a precipitação pluviométrica foi muito baixa, positiva, porém não significativa $(r s=0,016 p>0,05)$, indicando que esse fator climático não foi o principal responsável pela queda de flores de inajá, a qual, provavelmente, foi causada pela ação de outros fatores climáticos, como temperatura e insolação, e pelas condições endógenas da própria espécie, como o longo período de floração, ou mesmo pela ação de fatores bióticos, como baixa frequência de agentes polinizadores.

Ruiz \& Alencar (2004), em Manaus, AM, também não encontraram nenhuma correlação significativa entre a precipitação pluviométrica e a fenofase espatas abertas com flores caídas para a palmeira patauá.

Nesse sentido, registros na literatura mostram que a fenofase de floração de espécies florestais, inclusive de palmeiras, nem sempre é regular e sazonal, podendo ocorrer entre as estações seca e chuvosa (Henderson et al., 2000; Reys et al., 2005; Pereira et al., 2008; Pinto et al., 
2008; Sampaio \& Scariot, 2008; Freitas et al., 2010; Muniz, 2008; Tonini, 2011), isso porque a floração pode variar ano a ano, como consequência de irregularidades climáticas (Rubim et al., 2010).

Resultado diferente foi obtido para a floração da Atallea phalerata Mart. Ex Spreng em Bonito, MS, o qual não apresentou correlação significativa com precipitação e temperatura (Reys et al., 2005). A título de exemplo, Pereira et al. (2008), ao estudarem a correlação entre floração e precipitação pluviométrica de 58 espécies florestais, inclusive as palmeiras Astrocaryum aculeatissimum (Schott) Burret e Bactris setosa Mart., demonstraram, com base no coeficiente de Spearman ( $r s=0,6102 ; p<0,0000$ ), que existe correlação positiva significativa dessa fenofase com a precipitação mensal e com as temperaturas médias mensais ( $\mathrm{rs}=0,7490$; $\mathrm{p}<0,0015)$.

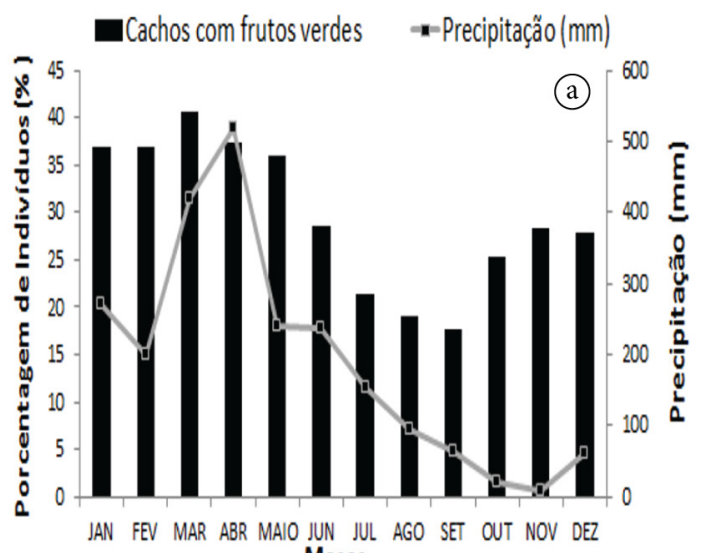

Meses
Como se percebe, a influência da precipitação sobre a floração de palmeiras, em geral, varia de acordo com a espécie e depende das condições edafoclimáticas locais ou, ainda, pode sofrer influência de fatores bióticos.

A frutificação do inajá, por sua vez, teve início com a fenofase cacho com frutos verdes, finalizando com a fenofase cacho com frutos maduros caindo. Essas fenofases ocorreram simultaneamente em um mesmo indivíduo. A fenofase cacho com frutos verdes ocorreu em todo período de monitoramento fenológico, porém se intensificou no período mais chuvoso (Figura 2a).

A maior porcentagem de frutos verdes $(40,1 \%)$ foi registrada em março, mês de maior precipitação média $(419,4 \mathrm{~mm})$, enquanto a menor $(17,7 \%)$ ocorreu em setembro, com precipitação pluviométrica média de $64,4 \mathrm{~mm}$, no período de menor pluviosidade. O baixo percentual de frutos verdes, ao longo do período de

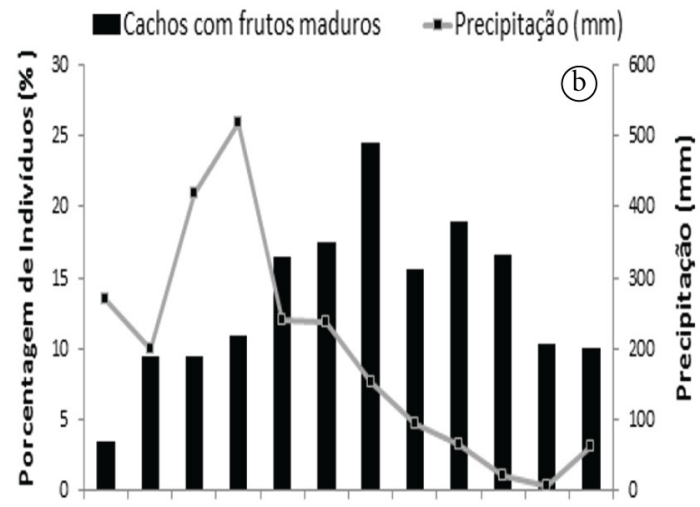

JAN FEV MAR ABR MAIO JUN JUL AGO SET OUT NOV DEZ Meses

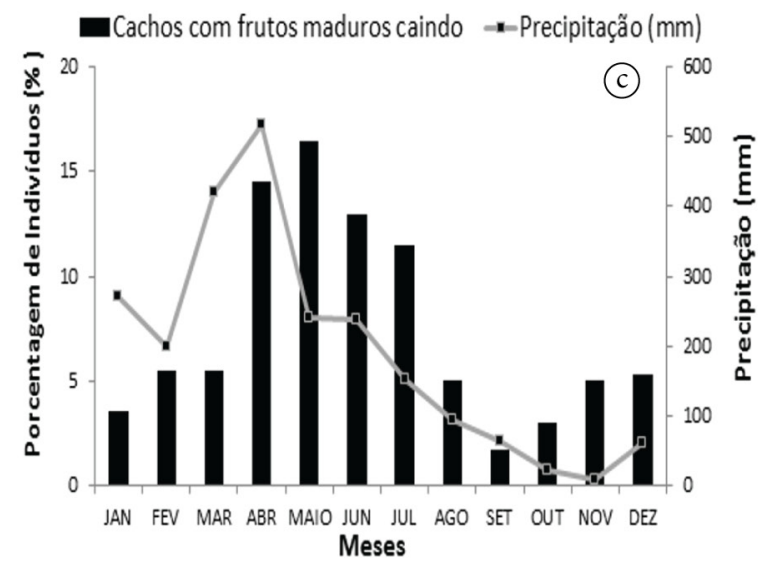

Figura 2. Percentagem de indivíduos de Attalea maripa (inajá) com cachos com frutos verdes (2a), cachos com frutos maduros (2b) e cachos com frutos maduros caindo (2c) no período de agosto de 2009 a dezembro de 2011, em Bonito, PA.

Figure 2. Percentages of individuals Attalea maripa (inajá) with bunches with green fruit (a), bunches with ripe fruit (b) and bunches with ripe fruit falling (c), from August 2009 to December 2011, in Bonito-PA. 
estudo, foi ocasionado, sobretudo, pela queda de flores, mencionada anteriormente.

A análise de correlação de Spearman mostrou que a fenofase de cachos frutos verdes de inajá está correlacionada de forma moderada e positiva com a precipitação pluviométrica ( $\mathrm{rs}=0,437$; $\mathrm{p}<0,05$ ). Isso pode ser explicado pelo fato de a presença de água no solo promover melhores condições hídricas e disponibilidade de nutrientes para o florescimento e, consequentemente, para o desenvolvimento dos frutos.

A ocorrência de cacho com frutos maduros de inajá, apesar de oscilar (Figura 2b), também foi observada durante todo o período de estudo em Bonito, PA. O maior percentual médio mensal (24,5\%) de cachos maduros foi registrado no mês de julho, com precipitação média de 153,35 mm, e o menor percentual (3,5\%) em janeiro, com média de $271 \mathrm{~mm}$.

Nota-se por esses resultados que o percentual de indivíduos de inajá com cachos com frutos maduros foi, em geral, baixo, em face do longo período de frutificação e da baixa sincronização desse evento fenológico, aliados à baixa produção de frutos verdes. O longo período de floração e frutificação de inajá, por outro lado, poderá favorecer a coleta de frutos ao longo do ano, bem como garantir o fornecimento de matéria-prima (frutos), no caso de industrialização para produção de óleo, e o manejo sustentável de sua população natural na Amazônia.

A correlação entre a fenofase de cacho com frutos maduros e a precipitação foi negativa e próxima de zero ( $r s=-0,056 ; p>0,05$ ), sugerindo que esse evento fenológico possivelmente não está relacionado à precipitação. Possivelmente, está relacionado às condições endógenas, ligadas à disponibilidade de nutrientes.

Assim como para o inajá, também não houve correlação entre precipitação e a fenofase cachos com frutos maduros para as palmeiras Oenocarpus bataua Martius (Ruiz \& Alencar, 2004), Attalea phalerata (Reys et al., 2005), Butia eriospatha (Mart. exDrude) Becc. e Syagrus romanzoffiana (Cham.) Glassman (Liebsch \& Mikich, 2009), sugerindo que a precipitação pluviométrica não é o fator climático mais expressivo para a frutificação de palmeiras tropicais.

A fenofase cacho com frutos maduros caindo de A. maripa ocorreu durante todo o período de estudo, sobretudo no término do período chuvoso (Figura 2c). A maior percentagem média (16,5\%) dos indivíduos com esse evento fenológico foi observada em maio, mês com pluviosidade média de $518 \mathrm{~mm}$, e a menor $(1,7 \%)$, em setembro, que apresentou em média $64,4 \mathrm{~mm}$ de pluviosidade.

A precipitação pluviométrica apresentou correlação positiva, moderada e altamente significante com a fenofase cacho com frutos maduros caindo ( $r s=0,495$; $\mathrm{p}<0,01$, revelando a influência desse fator climático na queda e dispersão de frutos maduros de inajá. Durante a pesquisa de campo foi observado que a dispersão do fruto do inajá é zoocórica e barocórica por gravidade.

A ocorrência dos maiores picos de queda de frutos maduros de inajá ao término do período chuvoso, aliado à correlação positiva com a precipitação, é um indicador de que a dispersão está associada a esse fator climático, com vistas a favorecer a germinação do pirênio (endocarpo mais amêndoa) e o estabelecimento de plântulas, fato observado durante o decorrer da pesquisa de campo em Bonito, PA.

A importância da precipitação na queda e dispersão de frutos é constatada em outras pesquisas sobre fenologia de espécies florestais, inclusive de palmeiras tropicais (Ruiz \& Alencar, 2004; Reys et al., 2005; Freitas et al., 2010).

A queda de folhas velhas de inajá, ou abscisão, foi observada ao longo do monitoramento fenológico (Figura 3), porém as copas não ficaram totalmente desfolhadas devido à emissão de folhas novas, denotando que o inajá é uma espécie perenifólia.

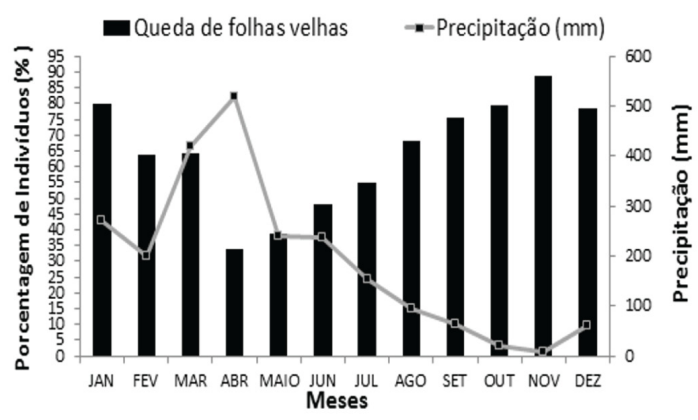

Figura 3. Porcentagens mensais de indivíduos de Attalea maripa (inajá) com queda de folhas velhas no período de agosto de 2009 a dezembro de 2011, em sistema silvipastoril, no município de Bonito, PA.

Figure 3. Monthly percentages of individuals Attaleamaripa (inajá) drop leaves, from August 2009 to December 2011 in a silvopastoral system in the municipality of Bonito-PA. 
Em geral, os maiores percentuais de queda de folhas de inajá ocorreram no período de menor precipitação pluviométrica. A maior queda de folhas (89\%) foi verificada em novembro, cuja precipitação foi muito baixa, igual a $7,5 \mathrm{~mm}$, e a menor queda (34\%) foi observada em abril, mês com precipitação média de $518 \mathrm{~mm}$. Nota-se na Figura 3 que a queda e a emissão de folhas de inajá não são eventos sazonais, mas contínuos.

A correlação entre essa precipitação pluviométrica e a queda de folhas foi moderada, negativa e altamente significativa ( $r s=-0,593 ; \mathrm{p}<0,01)$, denotando a influência desse fator climático na abscisão de folhas, devida, provavelmente, ao estresse hídrico provocado pela alta intensidade de radiação solar e à temperatura elevada. Portanto, esse comportamento fenológico do inajá pode ser uma resposta ecofisiológica ao estresse hídrico e a não disponibilidade de nutrientes no período de menor precipitação pluviométrica.

Estudos sobre padrão fenológico de palmeiras realizados na Amazônia e em outras regiões do Brasil também relataram ocorrência de queda de folhas na estação menos chuvosa devida ao estresse hídrico (Pereira et al., 2008; Rubim et al., 2010).

A emissão de folhas novas, por sua vez, foi observada ao longo do período de estudo em 100\% dos indivíduos adultos de inajá, revelando que esse é um evento fenológico contínuo. A emissão contínua de folhas também foi observada em Astrocaryum vulgare Mart. em Belém, PA (Oliveira et al., 2003).

O comportamento fenológico do inajá em relação à queda e à emissão de novas folhas denota a capacidade de adaptação dessa palmeira aos fatores edafoclimáticos predominantes na área de estudo, no nordeste paraense. Essa espécie apresenta potencial para ser cultivada e manejada nessa mesorregião, em que o solo e a cobertura vegetal encontram-se altamente alterados pela ação antrópica.

A adequação da utilização da análise fatorial para a base de dados gerada nessa pesquisa foi confirmada pelo teste de Kaiser-Meyer-Olkin $(0,511)$, pois valores acima de 0,50 indicam que essa ferramenta pode ser aplicada para análise do problema em estudo, bem como pelo teste de esfericidade de Bartlett, cujo valor de $p$ foi de aproximadamente zero $(0,000)$, ou seja, menor que o nível de significância $\alpha=5 \%$ (Hair et al., 2009).
Os autovalores e os componentes principais, obtidos a partir da decomposição espectral da matriz de correlação, são apresentados na Tabela 1. Os primeiros três componentes com autovalores maiores que 1 explicam quase $73 \%$ da variância total acima do mínimo aceitável, que é de 70\% (Hair et al., 2009). Os demais componentes explicam o percentual restante.

O resultado da matriz de cargas fatoriais, após a rotação ortogonal pelo método Varimax, revela a existência de três fatores (Tabela 2), constituídos pela inter-relação das variáveis que exercem um peso significativo na fenologia do inajá.

Os valores das comunalidades apresentados na Tabela 2 exprimem quanto cada variável é explicada por cada componente principal extraído e se essas variáveis foram bem representadas pelo componente principal ao qual elas pertencem (Hair et al., 2009).

O primeiro fator apresentou em sua composição três variáveis bióticas e uma abiótica, inter-relacionadas. As fenofases espata aberta com flores e queda de folhas velhas apresentaram interação negativa com a precipitação, já em relação à fenofase cacho com frutos maduros caindo houve interação positiva com a precipitação (Tabela 2). Em outras palavras, o aumento na precipitação diminui a emissão de espatas abertas com flores e a queda de folhas velhas, porém aumenta a queda de frutos do inajá e, por conseguinte, favorece o processo natural de regeneração dessa palmeira.

O segundo fator é composto pelas variáveis: espata fechada, espata aberta com flores caindo e espata aberta com flores caídas, as quais estão fortemente inter-relacionadas. A primeira variável interage negativamente com a segunda e com a terceira variável (Tabela 2).

O terceiro fator foi constituído por duas variáveis bióticas: cacho com frutos verdes e cacho com frutos maduros. A primeira variável apresentou carga fatorial negativa, enquanto a segunda apresentou carga fatorial positiva, revelando que a percentagem de frutos verdes diminui com o amadurecimento dos frutos, fato esse observado no processo natural de frutificação do inajá (Tabela 2).

Os resultados da análise fatorial, portanto, corroboram os resultados obtidos pela análise dos fenogramas e da correlação de Spearman e confirmam a importância da precipitação pluviométrica, isto é, da estação chuvosa, para a fenologia reprodutiva do inajá na Amazônia. 
Tabela 1. Resultados dos autovalores para a extração de fatores e variância total explicada pelos fatores.

Table 1. Results of the eigenvalues for the extraction of factors and the total variance explained by the factors.

\begin{tabular}{|c|c|c|c|c|c|c|}
\hline \multirow[b]{2}{*}{ Componentes } & \multicolumn{3}{|c|}{ Autovalores e variâncias iniciais } & \multicolumn{3}{|c|}{ Variância após rotação } \\
\hline & $\begin{array}{c}\text { Variância } \\
\text { total }\end{array}$ & $\begin{array}{c}\text { \% da } \\
\text { variância }\end{array}$ & $\begin{array}{c}\text { Variância } \\
\text { acumulada }\end{array}$ & $\begin{array}{c}\text { Variância } \\
\text { total }\end{array}$ & $\begin{array}{c}\% \text { da } \\
\text { variância }\end{array}$ & $\begin{array}{c}\text { Variância } \\
\text { acumulada }\end{array}$ \\
\hline 1 & 2,811 & 31,237 & 31,237 & 2,575 & 28,614 & 28,614 \\
\hline 2 & 2,352 & 26,129 & 57,366 & 2,414 & 26,825 & 55,439 \\
\hline 3 & 1,393 & 15,473 & 72,839 & 1,566 & 17,400 & 72,839 \\
\hline 4 & 0,874 & 9,715 & 82,554 & & & \\
\hline 5 & 0,685 & 7,616 & 90,169 & & & \\
\hline 6 & 0,457 & 5,073 & 95,242 & & & \\
\hline 7 & 0,182 & 2,021 & 97,263 & & & \\
\hline 8 & 0,137 & 1,518 & 98,781 & & & \\
\hline 9 & 0,110 & 1,219 & 100,000 & & & \\
\hline
\end{tabular}

Tabela 2. Matriz de cargas fatoriais após a rotação ortogonal pelo método Varimax.

Table 2. Matrix of factor loadings after Varimax orthogonal rotation method.

\begin{tabular}{lcccc}
\multicolumn{1}{c}{ Variáveis } & \multicolumn{3}{c}{ Fatores } & Comunalidades \\
\cline { 2 - 4 } & $\mathbf{1}$ & $\mathbf{2}$ & $\mathbf{3}$ & 0,856 \\
\hline Espata fechada & 0,034 & $-\mathbf{0 , 9 2 3}$ & 0,041 & 0,623 \\
\hline Espata aberta com flores & $\mathbf{- 0 , 7 8 7}$ & $-0,005$ & $-0,056$ & 0,739 \\
\hline Espata aberta com flores caindo & 0,067 & $\mathbf{0 , 8 4 5}$ & 0,144 & 0,718 \\
\hline Espata aberta com flores caídas & $-0,150$ & $\mathbf{0 , 8 3 3}$ & 0,044 & 0,822 \\
\hline Cacho com frutos verdes & 0,490 & $-0,225$ & $\mathbf{0 , 7 0 8}$ & 0,834 \\
Cacho com frutos maduros & 0,077 & $-0,294$ & $-\mathbf{0 , 8 6 1}$ & 0,421 \\
\hline Cacho com frutos maduros caindo & $\mathbf{0 , 6 3 2}$ & $-0,122$ & 0,080 & 0,848 \\
\hline Queda de folhas velhas & $\mathbf{0 , 8 2 9}$ & $-0,045$ & 0,398 & 0,695 \\
\hline Precipitação pluviométrica & $\mathbf{0 , 7 5 1}$ & $-0,006$ & 0,363 & - \\
\hline \% da variância & 28,614 & 26,825 & 17,400 & \\
\hline
\end{tabular}

Além disso, demonstram que a aplicação da análise fatorial adequa-se a ser utilizada em pesquisas que tratam da fenologia de espécies florestais, inclusive de palmeiras tropicais.

Ruiz \& Alencar (2004), ao empregarem análise de componentes principais para estudar a fenologia do patauá, também constataram que a precipitação apresentou alto poder discriminatório e maior contribuição na formação dos componentes principais, denotando, portanto, a importância desse fator climático na fenologia da palmeira patauá.

A importância da precipitação pluviométrica para a ocorrência de eventos fenológicos em Astrocaryum aculeatissimum, Bactris setosa e Euterpe edulis também foi observada por Pereira et al. (2008). Para os autores, o aumento de umidade do ambiente proporcionado pela chuva antes da antese, quebra o "descanso" dos primórdios florais imposto pelo período de estiagem, dando início ao processo de floração, o qual promove o processo de frutificação da espécie em estudo.

\section{CONCLUSÕES}

Pelo que a pesquisa evidenciou, o padrão fenológico da palmeira Attalea maripa (Aubl.) Mart. (inajá) não é sazonal. A floração e a frutificação ocorrem durante todo o ano, são eventos de longa duração e sofrem oscilações ao longo do ano. A fenofase espata fechada é altamente sincrônica, já a frutificação é um evento fenológico pouco sincrônico.

A precipitação é um fator climático importante para a fenologia do inajá, pois afeta negativamente a produção de espata aberta com flores e a queda de folhas e positivamente a queda de frutos maduros, funcionando como um veículo de dispersão natural dos frutos de inajá. 


\section{AGRADECIMENTOS}

À Fundação de Amparo à Pesquisa do Estado do Pará - FAPESPA, pelo financiamento da pesquisa. À Secretaria de Estado de Meio Ambiente (SEMA), pelo fornecimento dos dados meteorológicos. Aos moradores da Vila Cumaru, em especial aos senhores Francisco Benedito de Sousa e Raimundo Angélico Mininéia Lameira, pelo apoio durante o desenvolvimento desta pesquisa, bem como a toda a equipe do projeto Sistemas de Produção Sustentável de Inajá [Attalea maripa (Aubl.) Mart] para a recuperação de áreas degradadas e produção de biodiesel na agricultura familiar.

\section{STATUS DA SUBMISSÃO}

Recebido: 26 jun., 2013

Aceito: 10 jan., 2016

\section{AUTOR (ES) PARA CORRESPONDÊNCIA}

\section{Helaine Cristine Gonçalves Pires}

Instituto de Ciências Agrárias, Universidade Federal Rural da Amazônia - UFRA, Avenida Presidente Tancredo Neves, 2501, Terra Firme, CEP 66077-901, Belém, PA, Brasil e-mail: helainepires@yahoo.com.br

\section{REFERÊNCIAS}

Adler GH, Lambert TD. Spatial and temporal variation in the fruiting phenology of palms in isolated stands. Plant Species Biology 2008; 23(1): 9-17. http://dx.doi. org/10.1111/j.1442-1984.2008.00202.x.

Augspurger CK. Phenology, flowering, synchrony and fruit set of six neotropical shrubs. Biotropica 1983; 15(4): 257-267. http://dx.doi.org/10.2307/2387650.

Freitas JL, Santos MMLS, Oliveira FA. Fenologia reprodutiva de espécies potenciais para arranjo em sistemas agroflorestais, na Ilha de Santana, Amapá. Revista de Ciências Agrárias (Belém.) 2010; 1(53): 78-86. http://dx.doi.org/10.4322/ rca.2011.011.

Hair JF Jr, Black WC, Babin BJ, Anderson RE, Tatham RL. Análise multivariada de dados. 6. ed. Porto Alegre: Bookman; 2009. 688 p.

Henderson A, Fischer B, Scariot A, Pacheco MAW, Pardini R. Flowering phenology of a palm community in a central Amazon forest. Brittonia 2000; 52(2): 149-159. http:// dx.doi.org/10.2307/2666506.
Instituto de Desenvolvimento Econômico, Social e Ambiental do Pará - IDESP. Diretoria Estatística, Tecnologia e Gestão de informação. Estatística municipal: Município Bonito [online]. Belém: IDESP; 2011 [citado em 2011 mar 27]. Disponível em: http://iah. iec.pa.gov.br

Liebsch D, Mikich SB. Fenologia reprodutiva de espécies vegetais da Floresta Ombrófila Mista do Paraná, Brasil. Brazilian Journal of Botany 2009; 32(2): 375-391. http:// dx.doi.org/10.1590/S0100-84042009000200016.

Matos AKMG. Biometria e morfologia de Attalea maripa (Aubl.) Mart. (inajá) em sistema silvipastoril no nordeste paraense [Dissertação]. Belém: Universidade Federal Rural da Amazônia; 2010.

Mota RV, França LF. Estudo das características da Ucuúba (Virola surinamensis) e do Inajá (Maximiliana regia) com vistas à produção de biodiesel. Revista Científica da UFPA 2007; 6(1): 1-9.

Muniz FH. Padrões de floração e frutificação de árvores da Amazônia maranhense. Acta Amazonica 2008; 38(4): 617626. http://dx.doi.org/10.1590/S0044-59672008000400004.

Oliveira MSP, Couturier G, Beserra P. Biologia da polinização da palmeira tucumã (Astrocaryum vulgare Mart.) em Belém, Pará, Brasil. Acta Botanica Brasílica 2003; 17(3): 343-353. http://dx.doi.org/10.1590/S010233062003000300002 .

Ostrorog DRV, Barbosa AAA. Biologia reprodutiva de Geonoma brevispatha Barb. Rodr. (Arecaceae) em mata de galeria inundável em Uberlândia, MG, Brasil. Brazilian Journal of Botany 2009; 32(3): 479-488. http://dx.doi. org/10.1590/S0100-84042009000300007.

Pereira TS, Costa MLMN, Moraes LFD. LUCHIARI C. Fenologia de espécies arbóreas em Floresta Atlântica da Reserva Biológica de Poço das Antas, Rio de Janeiro, Brasil. Revista IHERINGIA 2008; 63(2): 329-339.

Pinto AM, Morellato LPC, Barbosa AP. Fenologia reprodutiva de Dipteryx odorata (Aubl.) Willd (Fabaceae) em duas áreas de floresta na Amazônia Central. Acta Amazonica 2008; 38(4): 643-650. http://dx.doi.org/10.1590/S004459672008000400006 .

Rech AR, Absy ML. Pollen storages in nests of bees of the genera Partamona, Scaura and Trigona (Hymenoptera, Apidae). Revista Brasileira de Entomologia 2011; 55(3): 361372. http://dx.doi.org/10.1590/S0085-56262011005000026.

Reys P, Galetti ML, Morellato PC, Sabino J. Espécies arbóreas em mata ciliar no rio Formoso, Mato Grosso do Sul. Biota Neotropica 2005; 5(2): 1-10. http://dx.doi. org/10.1590/S1676-06032005000300021.

Rubim P, Nascimento HEM, Morellato LPC. Variações interanuais na fenologia de uma comunidade arbórea de floresta semidecídua no sudeste do Brasil. Acta Botanica Brasílica 2010; 24(3): 756-764. http://dx.doi.org/10.1590/ S0102-33062010000300019. 
Ruiz RR, Alencar JC. Comportamento fenológico da palmeira patauá (Oenocarpus pataua) na Reserva Florestal Adolpho Duke, Manaus, Amazonas, Brasil. Acta Amazonica 2004; 34(4): 443-448. http://dx.doi.org/10.1590/S004459672004000400007.

Sampaio MB, Scariot A. Growth and reproduction of the understory palm Geonoma schottiana Mart. in the gallery forest in Central Brazil. Revista Brasileira de Botanica. Brazilian Journal of Botany 2008; 31(3): 433-442. http:// dx.doi.org/10.1590/S0100-84042008000300007.

Tannus JLS, Assis MA, Morellato LPC. Fenologia reprodutiva em campo sujo e campo úmido numa área de cerrado no sudeste do Brasil, Itirapina - SP. Biota Neotropica 2006; 6(3): 1-27. http://dx.doi.org/10.1590/ S1676-06032006000300008.

Tonini H. Fenologia da castanheira do Brasil (Bertholletia excelsa Humb. \& Bonpl., Lecythidaceae) no sul do estado de Roraima. Revista Cerne 2011; 17(1): 123-131. http:// dx.doi.org/10.1590/S0104-77602011000100015.

Vieira TA. Quintais agroflorestais de Bonito, Pará: socioeconomia e bem-estar de agricultores familiares, ecologia e química do solo [tese]. Belém: Universidade Federal Rural da Amazônia; EMBRAPA; 2011. 